\title{
2 ou 3 Choses que Je Sais D'Elle: o desenho conceitual de um território acústico
}

\section{2 ou 3 Choses que Je Sais D'Elle: the conceptual drawing of an acoustic territory}

Frederico Augusto Vianna de Assis Pessoa ${ }^{1}$ 


\section{Resumo}

Neste artigo, discutiremos as relações entre som e imagem no cinema, tendo como objeto o filme 2 ou 3 Choses que Je Sais D'Elle (1967) de Jean-Luc Godard. Inicialmente, identificaremos práticas hegemônicas de conexão entre som e imagem cinematográficos para que possamos, então, apontar os dissensos estéticos provocados por Godard. $O$ diretor, através do uso de procedimentos conceituais de criação sonora e articulação entre som e imagem, tece um território acústico complexo que solicita um processo de decifração pelo ouvinte/ espectador. Os acontecimentos sonoros mesclam sensorialidade, memória, emotividade, significação e, mesmo, imagem, constituindo multiplicidades que definimos como Territórios Acústicos. Analisaremos como o território acústico de 2 ou 3 Choses que Je Sais D'Elle desenha novas formas de articulação entre som e imagem e solicita, com isso, novas formas de relação entre o ouvinte/espectador e o cinema.

Palavras-Chave: Cinema, Banda Sonora, Dissenso Estético, Território Acústico.

\section{Abstract}

The purpose of this paper is to discuss the sound and image relations in cinema through the analyses of 2 ou 3 Choses que Je Sais D'Elle (1967) by Jean-Luc Godard. First, we will identify the hegemonic practices of sound and image connection in cinema and, afterwards, point out the aesthetic dissents provoked by the French director. Godard draws a complex acoustic territory applying conceptual procedures to create sound events and articulation between sound and image that demands a process of deciphering by the listener/spectator. Sound events conjoin sensibility, memory, emotions, meaning, and even image, composing multiplicities that we call Acoustic Territories. We will analyze how the acoustic territory of 2 ou 3 Choses que Je Sais D'Elle draws new forms of articulation between sound and image and thus calls for new forms of relation between listener/spectator and cinema.

Keywords: Cinema, Soundtrack, Aesthetic Dissent, Acoustic Territory.

ISSN: $1808-3129$

1 Doutorando em Artes - Poéticas Tecnológicas; Mestre em Artes - Cinema; Especialista em Filosofia Universidade Federal de Minas Gerais, Brasil fredericoz@hotmail.com 
Desde o seu início, ainda no final do século XIX, os registros cinematográficos tiveram sua fruição acompanhada, na maioria das situações de projeção, por alguma manifestação sonora: música ao vivo, sonoplastia, narradores e intérpretes in loco (KALINAK, 2010). Até meados da década de 1920, a música era o acompanhamento sonoro preferido, utilizando-se um piano ou, se possível, grupos musicais e, em alguns casos, orquestras.

As articulações que se constituíam durante os espetáculos entre ambos os fenômenos (ou linguagens), expressavam modos de sensorialidade particulares que solicitavam novas formas de construção de sentido. O audiovisual, mesmo em seu nascimento, já lidava com novas conjunções de forças em planos de composição estéticos nunca dantes experimentados (ao menos da maneira que ali se davam). Os territórios acústicos desenhados a partir da relação específica entre som e imagem técnica solicitavam e constituíam novas escutas, ao mesmo tempo em que erigiam geografias próprias: espaços virtualizados e reais mesclados na projeção sobre a tela, no local de fruição, na memória, na experiência vivida e na imaginação dos espectadores; na proximidade do objeto de escuta/olhar e em seu distanciamento; no desligamento do mundo compartilhado e no mergulho na experiência narrativa da tela.

Definimos a escuta como uma cartografia de relações, espaços e intensidades: um mapa "desmontável, reversível, suscetível de receber modificações constantemente" (DELEUZE; GUATTARI, 2000, p. 22). A escuta faz rizoma, pois "cadeias semióticas de toda natureza são aí conectadas a modos de codificação muito diversos, cadeias biológicas, políticas, econômicas, etc., colocando em jogo não somente regimes de signos diferentes, mas também estatutos de estados de coisas" (Ibid., p. 15). Definimos como Território Acústico esta multiplicidade variável que se articula em acontecimentos de escuta.

Os territórios acústicos, por seu caráter múltiplo e aberto, organizam-se a partir de conjuntos de $n$ eventos e processos de decifração que buscam compreendê-los, sendo tanto individuais quanto compartilhados. São territórios no sentido de espaços que tanto ocupamos quanto constituímos quando estabelecemos relações com o mundo através da escuta. Tais espaços não são físicos, embora possam envolver o espaço físico. São espaços que se desenham através da rede de sensações, memórias, saberes, etc., que se constitui na percepção e interpretação dos fenômenos acústicos. Tais espaços podem ser dados contingencialmente na experiência ou serem propostos através da estruturação de situações de escuta que solicitam processos específicos de decifração, como em obras artísticas sonoras ou sonoro-imagéticas (audiovisuais).

Ainda nas primeiras décadas do século $X X$, a união entre som e imagem no cinema se inseria em um arcabouço simbólico que definia modos de conexão entre os dois elementos e o sentido que expressavam. Este arcabouço possuía uma história que passava pelas artes cênicas, pela ópera e por outras formas de arte e entretenimento que envolviam imagens e sons (lanterna mágica, algumas formas de diorama, entre outros). Gorbman (1987) observa que a música, como era utilizada no cinema dos anos 1930/1940 (e na maioria dos filmes atuais), tinha finalidade mediadora, articulando diversos elementos da narrativa ao cruzar fronteiras "entre níveis da narração (diegético/não diegético), entre agentes da narrativa (narradores subjetivos/ 
objetivos), entre o tempo da projeção e o tempo psicológico, entre pontos do tempo e do espaço diegéticos (como transição da narrativa)" (GORBMAN, 1987, p. 30, tradução nossa).

A autora, em seu livro Unheard Melodies (1987), realiza um estudo sobre o cinema de narrativa clássica e a utilização do som neste tipo de narrativa. A partir da análise da prática compositiva para cinema entre os anos 1930 e 1940, Gorbman compila sete princípios que orientavam o uso da música nas narrativas clássicas hollywoodianas. O fato de tê-los localizado temporalmente na Hollywood dos anos 1930 e 1940, e partir da observação dos trabalhos de Max Steiner, compositor chave da época, não limitam tais práticas àquele período. A grande maioria das obras audiovisuais contemporâneas utiliza a metodologia clássica de conexão entre som e imagem identificada pela autora. Esta metodologia define um código hegemônico de constituição de relações entre som e imagem nas obras audiovisuais, o qual é compreendido pelo espectador a partir do contato continuado, da apreciação e da formação através das próprias obras ${ }^{1}$.

Os sete princípios elencados pela autora são os seguintes: 1) invisibilidade - o aparato técnico de registro e produção sonora não é visto; 2) inaudibilidade - a música não seria composta para ser percebida conscientemente; 3) a música é significante da emoção - a função da música é reforçar a emoção sugerida pela narrativa; 4) a música marca pontos de entrada ou mudança da narrativa - pontos de vista, localização, personagens, etc.; 5) a música provê continuidade - preenche lacunas temporais ou mudanças espaciais, etc.; 6) a música dá unidade ao filme - a própria estrutura da composição musical, bem como sua instrumentação, a repetição de melodias e variações melódicas, garantiriam uma unidade auditiva para o filme; 7) um dos princípios anteriores pode ser violado, desde que a serviço de outro deles. A autora afirma:

O objetivo da trilha musical 'clássica' é colocar o ouvido daquele que escuta em uma posição subjetiva harmoniosa com o olho daquele que vê: criar um corpo 'fantasmático' de identificação [...]. Isto nos leva ao cinema clássico hollywoodiano, o qual é baseado no corpo unificado do sujeito, no apagamento do discurso em favor da história, e em uma imersão do espectador nesse universo, que se assemelha a um transe (GORBMAN, 1987, p.7, tradução nossa).

A voz, assim como os ruídos, não faz parte das análises da autora, mas é elemento sonoro central na maioria das obras audiovisuais. Em narrativas clássicas (e em grande parte dos filmes comerciais contemporâneos), a banda sonora é estruturada de forma a enfatizar a voz e sua compreensão: música e ruídos têm seu volume reduzido ou se retiram da cena para que a voz possa ser escutada sem sua interferência. $A$ questão central (geralmente) não é a fidelidade nem a expressividade da voz, mas a inteligibilidade do discurso. No cinema clássico hollywoodiano analisado por Gorbman (bem como em inúmeras produções contemporâneas), os ruídos são vistos como complementos sonoros à verossimilhança do recorte feito pela imagem e os sons do mundo são reproduzidos de acordo com os eventos que a narrativa apresenta: carros que passam; portas que se abrem e fecham; animais que se manifestam; etc.

1 É importante lembrarmo-nos de que algumas das práticas utilizadas ainda hoje na construção dos territórios acústicos cinematográficos se originam em outras linguagens artísticas, como a ópera, a música programática e o melodrama. 
A construção clássica da relação entre imagem e som no audiovisual tornouse um sistema codificado e hierarquizado, um plano de organização que apresenta conexões pré-estabelecidas entre seus pontos; um espaço estriado ${ }^{2}$ que limita as possibilidades de criação poética. Isso não quer dizer que todas as funções dos sons já estejam pré-determinadas e nada se possa fazer a não ser preenchê-las. Caberia a cada artista se apropriar do código, experimentar seus limites e flexibilizar a rigidez que encontra. No entanto, a transformação cada vez maior da cultura em commodity, a homogeneização dos ouvintes/espectadores a partir da planificação do que lhes é oferecido e o domínio crescente da indústria cultural, reforçam a rigidez e a hegemonia do sistema como forma de produção em massa.

Por outro lado, rupturas se manifestam em obras audiovisuais que propõe modos de criação sonoro-imagética que constituem novos territórios acústicos e, com isso, produzem dissenso estético em relação às práticas hegemônicas de conexão entre som e imagem. Estas obras produzem novas articulações (sensorialidade e criação de sentido) tanto entre os sons, quanto entre som e imagem, e entre som e cultura/ouvinte a partir de suas propostas conceituais. Desta forma, atuam na redefinição do próprio sensível e operam a "interrupção das coordenadas normais da experiência sensorial" (RANCIÈRE, 2005, p. 15, tradução nossa). Como nos diz Jacques Rancière, a força artística está na criação de dissenso estético que atua no processo político de questionamento dos consensos; a força da arte está em "ser um espaço metamórfico, dedicado [...] à mescla das artes, dedicado a todas as formas mediante as quais as práticas artísticas constroem hoje em dia espaços inéditos" (Ibidem, p.71, tradução e grifo nossos).

O cineasta Jean-Luc Godard é apontado como um dos mais inovadores diretores da New Wave francesa e da história do cinema, com um estilo único que se renova ao longo de sua carreira. Godard cria planos estéticos ${ }^{3}$ particulares a partir de propostas conceituais de conexão entre som e imagem em muitos de seus filmes. 2 ou 3 Choses que Je Sais D’Elle é seu 13ㅇlonga-metragem, em uma lista que beira quase cem produções (entre curtas e longas-metragens e produções em mídias diversas). Esta obra faz parte de seus "mais ambiciosos trabalhos" (STERRITT, 1999, p. 27), como um filme-ensaio que não se enquadra em nenhum gênero tradicional. Analisaremos a proposta conceitual de Godard para a construção do diálogo entre som e imagem neste filme.

Partiremos da hipótese de que o diretor cria, em 2 ou 3 Choses que Je Sais D’Elle, uma série de princípios que definem as relações entre som e imagem. Estes princípios solicitam uma nova escuta a partir da constituição de um território acústico particular. Godard propõe como problema o enfrentamento do pensamento estético hegemônico representado pelos princípios sonoros do cinema clássico hollywoodiano e realiza este enfrentamento através da criação de procedimentos de dissensão estética que provocam a ruptura e a renovação do pensamento clássico. Tais procedimentos se expressam na tecedura do territóro acústico que podemos localizar em

2 O espaço estriado é caracterizado pela presença de normas que definem sua ocupação, modelos que determinam de forma fixa e regular as relações dos elementos que o compõem, bem como estruturas hierarquizadas de funções para tais elementos. 0 espaço liso, seu oposto complementar, se caracteriza pela fluidez em sua ocupação, sem modelos rígidos que definam as posições ou interações entre elementos de forma regular, bem como sem uma hierarquia prévia que defina as funções de cada elemento que o compõe (BOULEZ, 1972 e DELEUZE; GUATTARI, 2005).

3 Ver DELEUZE, Gilles; GUATTARI, Felix. Mil Platôs. Vol. 1 a 5. 
2 ou 3 Choses que Je Sais D'Elle, o qual se constitui a partir de todo um pensamento conceitual que orienta as escolhas sonoras e sua articulação com as imagens, como veremos a seguir.

Do silêncio, mergulhamos sem aviso nos sons de máquinas, veículos e motores em giro ritmado. Como em um letreiro luminoso que ocupa os espaços públicos das grandes cidades, piscam na tela os dizeres: 2 (azul) ou (branco) 3 (vermelho); são seguidos por Choses que Je Sais D'Elle (verde); e depois Elle|La Région Parisienne (em vermelho, azul e branco). Silêncio súbito sobre as imagens de um viaduto em construção. A câmera está posicionada em cima dele, mas vemos, graças a sua curvatura, o que se passa no espaço sobre o qual ele se assenta. A voz sussurrada do narrador relata a publicação de um ato normativo do estado que diz respeito à região administrativa de Paris. Vemos as imagens da construção, mas ouvimos unicamente seu sussurro. Inesperadamente somos invadidos, mais uma vez, pelo som avassalador da cidade: carros, motos, caminhões, motores, máquinas - a câmera sob o viaduto observa o tráfego que o ladeia. No próximo plano, o silêncio emoldura dois prédios altos como que circundados pelo viaduto. O narrador retoma sua fala sussurrada sobre a recém-criada unidade administrativa de Paris. Sob sua voz (único som que escutamos) as imagens de um vão de um prédio, onde vemos pessoas a caminhar.

Um plano fechado de uma mulher que olha para a câmera. Ela parece estar na varanda de um apartamento ou no corredor aberto de uma série de apartamentos. Escutamos sons ao fundo com certa reverberação. O narrador sussurra seu nome (o nome da atriz), Marina Vlady, e a descreve de forma superficial. Ela fala para a câmera, citando Brecht: "[o ator deve] falar como que citando a verdade". Ele diz: "Agora, ela vira o rosto para a direita, mas isso não é importante". O mesmo plano se repete. 0 narrador sussurra o nome da personagem, Juliette Janson, que vive ali, e a descreve de forma superficial. Ela fala como se conversasse com quem está atrás da câmera, mas não ouvimos as intervenções desta pessoa. Ao final, o narrador diz: "agora ela vira a cabeça para a esquerda, mas isso não é importante". Mais uma vez somos lançados nos ruídos da construção em um plano curto de um guindaste que se move.

Esta é a descrição dos três primeiros minutos do filme 2 ou 3 Choses que Je Sais D'Elle (1966) de Jean-Luc Godard. O filme aborda a Região Parisiense, como diz o título, mas também a vida cotidiana de Juliette Janson, jovem dona-de-casa de Paris que se prostitui. No entanto, o filme não se restringe a estes temas, pois expressa uma reflexão calcada em fragmentos de som e imagem acerca da sociedade capitalista, valores, publicidade, imperialismo norte-americano, diferenças de gênero, guerra, linguagem, linguagem cinematográfica, imagem, sexo, entre outros temas.

2 ou 3 Choses que Je Sais D'Elle em seus três primeiros minutos, descritos acima, já traz algumas pistas sobre o modo de articulação entre as matérias-primas básicas utilizadas na construção de seus sentidos. O primeiro aspecto conceitual que podemos observar já aqui (e que será confirmado ao longo do filme) é que - Princípio I - os sons são matéria de construção expressiva que se aliam às imagens para constituir campos de sentido, não se restringindo a acompanhar as imagens ou trazer o mundo objetivo para a tela. A partir deste pensamento, Godard libera o som de suas amarras realistas, tornando irrelevante a dicotomia, já clássica, entre sincronia e assincronia. A questão passa a ser tratar o som como matéria poética, como matéria 
que constitui planos estéticos junto com as imagens. As oposições ou diferenças se constroem entre os planos sonoros e, a partir daí, constituem sentidos que não estão em cada um separadamente.

Logo no início do filme, saltamos do silêncio para a grande intensidade sonora das máquinas acompanhadas pelos letreiros tremeluzentes - somos lançados de nossas cadeiras para o centro da massa sonora opressora da vida em comum nos centros urbanos, marcada pelos ruídos do mundo moderno e pela publicidade - som e imagem que se aglutinam em universos simbólicos, mas ao mesmo tempo imanentes. Dali, sem aviso, vemos uma imagem da cidade: a aridez do concreto armado que constrói monumentos às máquinas e ao capital. Imagem já antecipada pelo som, mas envolvida pelo silêncio súbito que a torna ainda mais árida do que nos parece em sua realidade cotidiana: monumento ao vazio, ao nada.

O narrador sussurra. Ele não quer se impor sobre a imagem, sobre o nosso pensamento, sobre a massa sonora que a cidade já constitui. Ele se opõe sonoramente ao espaço opressor sobre o qual fala a partir da relação sonora que estabelece com ele. O narrador fala aos nossos ouvidos; ele fala com a boca colada aos nossos ouvidos, como alguém que solicita nossa atenção e nos transfere o dever de capturar o que é dito; ele fala quase de dentro de nossos ouvidos, como voz da consciência que talvez deseje despertar.

O narrador se depara com a atriz. Sua enunciação reproduz a imagem sem, no entanto, ser capaz de dominá-la - diríamos que a descreve. Algo escapa. Algo está a menos e a mais na imagem e na enunciação. Ele termina a frase com "Eu não tenho certeza". A fala, expressão sonora de uma percepção (nesse caso), se restringe a nomear o que vê a partir de quem enuncia, criando um espaço paralelo (o espaço da linguagem) que não contém a imagem nem é contido por ela. Princípio II: O discurso "dança" junto com a imagem. Não se impõe a ela, mas também não é dominado por ela. O discurso não é revelação da verdade oculta na imagem, pois "eu não tenho certeza" sequer de fatos aparentemente objetivos. Falar em 2 ou 3 Choses que Sais $D^{\prime} E l l e$ é tão ensaístico quanto filmar.

A atriz é identificada e se expressa olhando para a câmera como se conversasse conosco. Cita Brecht. O narrador a identifica novamente, agora como personagem. Ela fala, mais uma vez olhando para a câmera, mas responde a perguntas que não escutamos sobre si e sua vida como personagem. Os discursos estabelecem relações de proximidade e afastamento, atravessando espaços distintos e mesclando ficção e realidade. Talvez questionem a separação entre ambas e a própria ideia de representação: "é preciso ressaltar que o filme, o cinema, a representação não estão fora do mundo. Não estão diante do mundo, olhando-o de fora, são eles próprios pedaços do mundo, são aquilo que do mundo se torna olhar" (COMOLLI, 2008, p. 82-83).

Robert, marido de Juliette, escuta o rádio com fones de ouvido ao lado de seu amigo Roger. Ele relata o que ouve: o presidente americano falando sobre sucessivos bombardeios justificados pela falta de atendimento do oponente a suas demandas. Ao final da sequência, escutamos os sons das bombas em um fortíssimo, atrelados às imagens dos componentes do rádio. A dupla articulação - meios de comunicação de massa e imposição violenta de uma perspectiva - aparece como espelho da sociedade capitalista contemporânea. 
Aos 10 minutos de filme, o filho, criança, de Juliette conversa com ela sobre um sonho que tivera na noite anterior. Ele relata que sonhou que andava sozinho na beira de um penhasco. Avistou dois gêmeos andando, lado a lado, em sua direção. Como o espaço era exíguo, ele se questionou sobre como iriam fazer ao cruzar com ele. Então, um dos gêmeos foi em direção ao outro e ambos se fundiram em uma só pessoa. Logo ele descobriu que aquelas duas pessoas eram o Vietnã do Norte e o Vietnã do Sul. Desta forma, percebe-se que todos podem ser porta-vozes das reflexões políticas que o filme realiza, independente da verossimilhança ou pertinência da enunciação em dado momento e contexto. Não há limites para o trânsito horizontalizado do discurso, nem tampouco para a bricolagem de temas, vozes, formas e sons. Logo após, o garoto pergunta para a mãe (Juliette): "O que é a linguagem?". Ela responde, heideggeriana: "É a morada do homem".

Mais à frente no filme, por volta dos 17 minutos, Juliette está em uma loja de roupas. A câmera a acompanha, inicialmente, e passa a acompanhar uma atendente. Em um meio primeiro plano vemos a atendente que olha para câmera e diz: "Eu saio às sete horas. Tenho um encontro com Jean-Claude às oito horas. Vamos a um restaurante e depois ao cinema". A não hierarquização da voz, no sentido apontado acima, se manifesta nas falas dos personagens secundários, personagens quaisquer, mas que aqui são alguém. Alguém que tem uma vida para além do que vemos, uma densidade que não se revela na imagem, mas que faz parte de cada uma dessas pessoas. São personagens, mas são parte da cidade, da região administrativa de Paris, parte da constituição das relações sociais tecidas nos espaços e nas formas possíveis de convivência dentro dos sistemas sociais que o filme aborda. A identidade não se revela na imagem, mas solicita a enunciação como expressão e construção de si - e aqui lhe é concedida. A escuta se torna escuta do outro. "A injunção do escutar é a interpelação total de um indivíduo a outro: coloca acima de tudo o contato quase físico desses dois indivíduos (pela voz e pelo ouvido): cria transferência: 'escute-me' quer dizer: toque-me, saiba que eu existo" (BARTHES, 1990, p. 222, grifos do autor).

Por volta dos 36 minutos, uma mulher, aparentemente registrada de forma documental, fala das dificuldades de conseguir um emprego adequado devido a sua idade e qualificação. $O$ discurso transita entre a ficção e o documentário, mesclando a mise-em-scène dos atores à auto-mise-em-scène do indivíduo filmado, cujo corpo "se destina ao filme, consciente e inconscientemente, se impregna dele, se ajusta à operação de cinematografia" (COMOLLI, 2008, p.85).

Um pouco mais à frente, Juliette está no cabelereiro e, enquanto lava os cabelos e conversa com pessoas ao seu redor, mescla pensamentos exteriorizados aos diálogos que estabelece com os demais personagens:

Manicure: - Que bronzeado, onde você andou?

Juliette: - Rússia.

Manicure: - Onde?

Juliette: - Silêncio. Leningrado.

Manicure: - Os russos são agradáveis?

Juliette: - Felicidade. São como todo mundo.

Manicure: - Estava só perguntando...

Juliette: - Eles são simpáticos. Alguns ruídos. 
O discurso transita entre o dentro e o fora, mescla superfície e profundidade; a fragmentação do pensamento interno e a trivialidade da conversa casual;

Princípio III - decorrente do Princípio II - Não há hierarquia para a voz: ela pode ser parte da narrativa, mas pode também ser uma reflexão sobre ela; pode pertencer ao narrador ou distribuir-se entre os personagens; partilhar o pensamento com todos os envolvidos; dar voz a; articular o que está separado pelos limites da tela, por dentro e por fora; afirmar que o cinema é uma construção, mas é também realidade.

Por volta dos 24 minutos de filme, Juliette está em um café e encontra uma amiga. Conversam rapidamente. Enquanto as acompanhamos, escutamos os sons fortes da máquina de pin-ball que havíamos vislumbrado rapidamente quando ela entrou no café. Ela sai da mesa para comprar um cigarro e a câmera a acompanha até encontrar outra personagem que começa a falar de si, nos olhando de frente. Durante sua fala, ouvimos os ruídos do pin-ball, dos veículos cruzando a rua em que se encontra o café, bem como os ruídos das outras pessoas e de ações diversas que não vemos (mas que se dão ali dentro) em intensidade igual ou maior à voz que enuncia. Princípio IV (em parte decorrente do Princípio I) - Não há hierarquia entre os sons, todos têm o mesmo valor. O mundo está repleto de sons que se combinam, se sobrepõem, se conectam. A voz e os ruídos são alguns deles, e podem ser intercambiados.

Após as primeiras cenas do filme, vemos o silêncio tornar-se, cada vez mais, parte da banda sonora. Ao longo da película, acompanhamos diversas cenas da cidade e das construções em seu movimento contínuo e ritmos múltiplos, articuladas ao silêncio da banda sonora. Parecem fazer-nos mergulhar ainda mais no fluxo sonoro-imagético construído pela colagem de Godard: as intensidades, modulações, multiplicidades. A presença do silêncio ressalta a convocação à escuta feita pelo filme - "não há silêncio que não esteja pleno de sons" (CAGE, 1973, p.135). Colocamonos à escuta, na disponibilidade para apreender (sentidos, conexões, pensamentos?) o que se manifesta na ausência/presença do som roçando as imagens. Assim, nos damos conta de que - Princípio $V$ - o silêncio em 2 ou 3 Choses que Je Sais D'Elle não é ausência de sons, mas uma eloquência muda que sua presença provoca.

Aos quase sete minutos, vemos o cartaz de Made in USA (filme de Godard de 1966) enquanto ouvimos o narrador dizer: "Querido George Washington, que loucura te fez assumir o papel de William Pritt". Logo a seguir vemos um recorte de uma caixa de sabão em pó da qual só vemos o nome: PAX. Junto à imagem, o narrador fala: “Pax Americana: lavagem cerebral supereconômica". Aqui e ali vislumbramos fragmentos de letreiros luminosos, de placas de identificação de companhias diversas. O letreiro Sunic é recortado pela câmera em Unic (equivalente sonoro de unique), enquanto escutamos a trabalhadora que descreve sua formação e experiência que a destacam dos demais, mas diz não encontrar trabalho devido a sua idade. Robert, o marido de Juliette, a aguarda encostado a uma parede repleta de fragmentos de papel, resíduos de cartazes arrancados. Resta apenas um onde se lê/vê: Paz no Vietnã - Ações/ Exigências. Juliette caminha em direção a ele. Ouvimos um som ensurdecedor que parece uma bomba explodindo. A cena se repete enquanto ouvimos a voz dela dizer: "O que devemos fazer". Alguém responde em off: "Recomeçar".

Em certo momento, diz o narrador: "Há uma interação cada vez maior entre imagens e linguagem. Pode-se dizer que viver na sociedade hoje é quase como viver 
numa ampla tira de quadrinhos". Mas os cartazes não aparecem unicamente como uma crítica a um modo de vida capitalista em que somos continuamente bombardeados por imagens e/ou mensagens que solicitam (ou criam) o desejo. Aparecem compondo camadas de sentido que se dão em sua inserção como duplo: imagem e imagem acústica - fusão entre matérias díspares. Sob o cartaz de Made in USA, temos a crítica à violência americana impondo seu modo de vida (produzido nos EUA) sobre os outros países, principalmente a França. A similaridade da situação a conecta a William Pritt impondo a dominação inglesa na guerra dos Sete Anos contra os franceses - mensagens complementares que aparecem no entrelaçamento da voz do narrador e do texto gráfico. Sob o sabão em pó $\mathrm{PAX}^{4}$, a lavagem cerebral supereconômica americana, a paz sob o novo imperialismo do capital. Desta forma, vemos que o som pode tornar-se imagem e ao mesmo tempo ser som. Princípio VI: não há hierarquia na relação som/imagem: há interações, deslizamentos, sobreposições e, até mesmo, troca de papéis.

Por volta dos oito minutos de filme, Juliette relata para a câmera um fragmento de experiência em que ela escuta uma voz que lhe soa como um "tipo de prova de outra existência". Ela diz: "Eu estava lavando os pratos. Comecei a chorar. Escutei uma voz que me disse: Você é indestrutível. Eu, eu mesma, todo mundo". Por baixo da última parte de sua fala, um curtíssimo trecho de música em instrumentos de corda. Robert a chama em off. Ela continua: "Está tudo confuso. O tempo... Não sei... Não, uma definição não me vem necessariamente". Robert: "Juliette! Roger está indo!".

Ao final da cena descrita mais acima, onde o filho de Juliette lhe conta um sonho sobre gêmeos que representavam o Vietnã dividido, ele pergunta sobre o que é a linguagem. Ela lhe responde: "A morada do homem". Juliette olha por um momento para a câmera, e a música de cordas soa por alguns segundos.

Mais à frente, por volta dos 26 minutos, vemos Juliette em um close, dentro de um café. Vemos uma revista feminina sendo folheada. Vemos outra mulher, também em close. Novamente vemos imagens da revista sendo folheada. Sob as imagens, o narrador comenta: "Esta é a maneira com que Juliette, às $03 \mathrm{~h} 37 \mathrm{~min}$, folheou as páginas... De um objeto conhecido na linguagem jornalística como revista. E esta é a maneira como, 150 quadros depois, outra jovem mulher, sua gêmea, viu o mesmo objeto. Onde, então, está a verdade? De frente ou de perfil? Mas, primeiro, o que é um objeto?" Vemos a mulher, a "gêmea" de Juliette, olhar para esta última. Vemos, no silêncio, imagens da revista. Os rostos de uma de outra das mulheres. Juliette franze as sobrancelhas e inicia-se um pequeno trecho musical enquanto vemos seu rosto olhando para o lado.

A música, embora tenha características associadas à emotividade (assim identificadas após um longo percurso na história da música e do cinema), nem sempre está conectada a situações em que a emoção que ela reforçaria se faz presente. Ora temos revelações de Juliette/Marina; ora uma afirmação filosófica; ora uma situação que solicita a reflexão. Princípio VII: a música não é o "significante da emoção" (GORBMAN, 1987, p. 73, tradução nossa), nem tampouco se prende a momentos dramáti-

4 De acordo com o dicionário de inglês online dictionary.com, Pax significa "um período na história marcado pela ausência de guerras significativas, usualmente imposto por uma nação predominante" (tradução nossa). 
cos, mas passeia com a imagem e se faz presente ocupando um lugar que poderia ser ocupado por qualquer outro som.

Desta forma, percebemos que as articulações entre som e imagem em 2 ou 3 Choses que Je Sais D'Elle fazem parte de uma proposta conceitual estruturada por Godard. Não se trata unicamente de constituir relações inesperadas entre som e imagem, mas propor modos de sensorialidade e construção de sentido que se dão nas articulações propostas pelo diretor.

Os sete princípios, ou conceitos gerais, que orientam a tecedura do território acústico que Godard desenha para este filme formam uma proposta conceitual para a constituição de articulações entre som e imagem. Tornam-se, assim, coordenadas para o desenho de territórios acústicos em espaços lisos (BOULEZ, 1972 e DELEUZE; GUATTARI, 2005). Os espaços lisos são espaços em que a distribuição de objetos, ou a realização de cortes, não são determinados de forma rígida, mas permitem uma distribuição irregular ${ }^{5}$. Embora o arcabouço tecido pelos princípios godardianos determine formas específicas de ação sobre o som (de certa forma criando um padrão), a abertura que caracteriza tais propostas permite $n$ possibilidades de distribuição dos materiais, $n$ possibilidades de articulação entre eles e de níveis de intensidade de cada um. Assim, não se trata de uma organização hierarquizada, rígida, mas de uma cartografia possível de forças envolvidas no desenho destes territórios acústicos que podem variar ao infinito.

Destacamos abaixo os princípios que localizamos para que tenhamos uma visão de seu conjunto:

Princípio I - sons são matéria de construção expressiva que se aliam às imagens para constituir campos de sentido, não se restringindo a acompanhar as imagens ou trazer o mundo objetivo para a tela;

Princípio II - O discurso "dança" junto com a imagem. Não se impõe a ela, mas também não é dominado por ela;

Princípio III - Não há hierarquia para a voz: pode ser parte da narrativa, mas pode também ser uma reflexão sobre ela; pode pertencer ao narrador ou distribuir-se entre os personagens; partilhar o pensamento com todos os envolvidos; dar a voz a; articular o que está separado pelos limites da tela, por dentro e por fora; afirmar que o cinema é uma construção, mas é também realidade;

Princípio IV - Não há hierarquia entre os sons, todos têm o mesmo valor;

Princípio $V$ - o silêncio não é ausência de sons, mas uma eloquência muda que sua presença provoca ao entrar em agenciamentos com as imagens;

Princípio VI - não há hierarquia na relação som/imagem: há interações, deslizamentos, sobreposições e, até mesmo, troca de papéis;

Princípio VII - a música não é o significante da emoção, nem tampouco se prende a momentos dramáticos, mas passeia com a imagem e se faz presente ocupando um lugar que poderia ser ocupado por qualquer outro som.

Estes sete princípios conceituais de orientação das relações entre som e imagem se manifestam em diversas formas no filme, como pudemos ver acima. E poderiam produzir um filme completamente diferente deste. Ou seja, não se trata de fixar

5 Ver a nota $n^{0} 2$ 
valores imutáveis para aspectos do som ou tipos de sons presentes na banda sonora, mas de permitir que relações específicas possam ser constituídas a partir de princípios conceituais abertos a materializações díspares. Cada obra que viesse a lançar mão destes mesmos princípios poderia ser única.

As propostas de relação entre som e imagem em 2 ou 3 Choses que Je Sais D'Elle se opõe às práticas utilizadas nas narrativas clássicas (GORBMAN, 1987; BORDWELL, 1985). O filme de Godard provoca um dissenso estético em relação à forma hegemônica de pensar tais relações, desobedecendo a princípios estabelecidos que definem papéis específicos e modos de articulação determinados entre som e imagem: a) a voz deve ser o centro de organização sonora, solicitando a ausência ou a redução da intensidade dos demais sons quando se faz presente - se estrutura nos discursos de forma a ser compreendida pelo espectador e permitir o desenvolvimento das ações, da narrativa e do arco dramático; b) os ruídos devem ser marcados pela verossimilhança e não se sobreporem aos demais elementos da banda sonora sem que haja uma razão dramática para tanto; c) a música reforça a emoção sugerida pela narrativa, provê continuidade; não deve ser percebida conscientemente pelo ouvine/ espectador; garante unidade ao filme e marca pontos de entrada ou mudança da narrativa.

Avoz - o discurso - em 2 ou 3 Choses que Je Sais D'Elle é vacilante, reflexiva, circular, descentrada (já que se dilui entre narrador, personagens e atores). As formas com que se manifesta não se impõem sobre os demais elementos da banda sonora, nem tampouco conduzem as ações da narrativa. Conduzem a narrativa experimental reflexiva e divagante que Godard cria, em parte no improviso, para este filme.

Os ruídos são elementos tão importantes quanto qualquer outro na banda sonora de 2 ou 3 Choses que Je Sais D'Elle. Como dissemos, entram tanto de forma realista como poética. Deslizam em composições sensoriais e de sentido com outros elementos, sonoros e imagéticos.

A música aparece tímida, pontuando momentos díspares, onde nem sempre encontramos a "emoção sugerida pela narrativa". Ela não dá unidade ao filme - já que esta é alcançada pelo pensamento fragmentário do narrador, das personagens e atores/atrizes - nem pontua momentos de mudança da narrativa.

Para além da dissensão em relação a um espaço estriado, hierarquizado e mais enrijecido representado pelas práticas de articulação entre som e imagem no cinema clássico, o filme de Godard, através dos procedimentos artísticos que utiliza, provoca rupturas nas formas padronizadas de constituição de sentido no cinema. Sua narrativa não evoca o drama, a solução de conflitos e a realização de objetivos. Há percursos sem objetivo final, traços que conectam pontos de várias formas, fluxos que são apanhados momentaneamente em expressões de pensamento, sons e imagens. A dissensão de 2 ou 3 Choses que Je Sais D'Elle se dá também em relação às formas tradicionais de pensar através de sons e imagens. Mais do que fazer cinema, trata-se de constituir blocos poéticos que coordenam o sonoro e o imagético em manifestações do viver, do sentir e do pensar.

Este é um filme ensaio em que Godard reflete, com e através de seus personagens/atores, sobre "a prostituição; a região parisiense; o banheiro que $70 \%$ dos franceses não têm; as terríveis leis dos complexos habitacionais; o ato físico do amor; 
a vida hoje; a guerra no Vietnã; a garota de programa moderna; a morte da beleza moderna; a circulação de ideias; a polícia secreta das estruturas" (LEVITIN, 2014, p. 236, tradução nossa); e para conduzir suas reflexões, lança mão dos procedimentos conceituais de estruturação de relações entre sons e imagens que discutimos acima. O diretor afirma que neste filme ele está o tempo todo perguntando: "Eu me vejo filmando e você me ouve pensar alto. Em outras palavras, isto não é um filme, é uma tentativa de filmar e é apresentado como isto mesmo. Ele realmente faz parte de minhas pesquisas pessoais. Não é uma história. Mas, espero, um documento" (GODARD apud NARBONI, 1972, p. 239 tradução nossa).

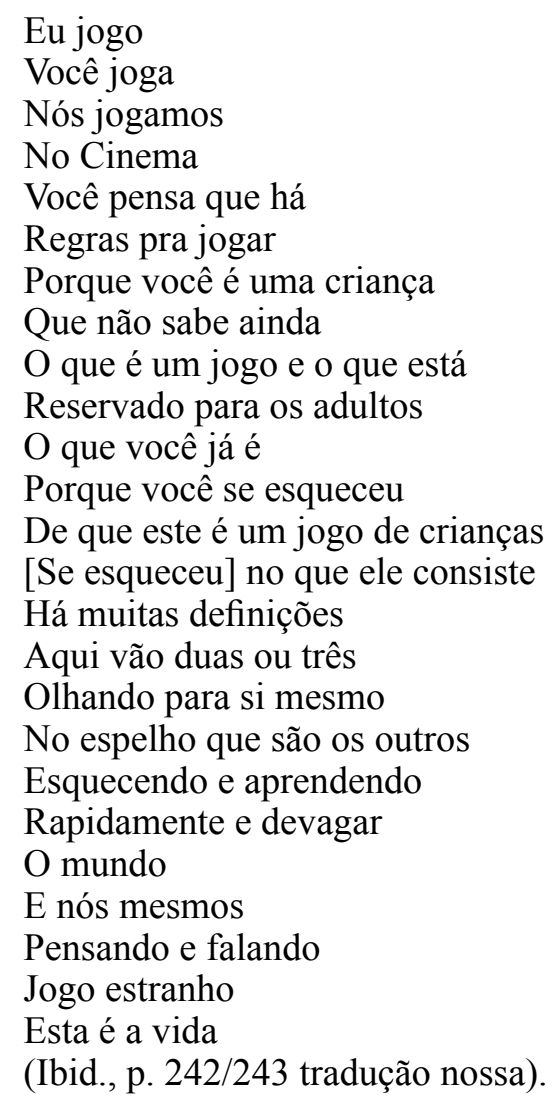

\section{Referências}

BARTHES, Roland. A Escuta. In BARTHES, Roland. O Óbvio e o Obtuso. Rio de Janeiro: Editora Nova Fronteira, 1995. pp 217-229.

BORDWELL, David. Narration in the Fiction Film. Madison: The University of Wisconsin Press, 1985.

BOULEZ, Pierre. A Música Hoje. São Paulo: Editora Perspectiva, 1972.

CAGE, John. Silence. Middletown: Wesleyan University Press, 1973.

COMOLLI, Jean-Louis. Ver e Poder. A inocência perdida: cinema, televisão, ficção, 
documentário. Belo Horizonte: Editora UFMG, 2008.

DELEUZE, Gilles e GUATTARI, Félix. Mil Platôs: capitalismo e esquizofrenia. Vol. 1. Reimpr. São Paulo: Editora 34, 2000.

Mil Platôs: capitalismo e esquizofrenia. Vol. 4. 2ª Reimpr. São Paulo: Editora 34, 2005.

GORBMAN, Claudia. Unheard Melodies. Bloomington: Indiana University Press, 1987.

KALINAK, Kathryn. Film Music: a very short introduction. New York: Oxford University Press, 2010.

LEVITIN, Jacqueline. One or Two Points About Two or Three Things I Know About Her. In CONLEY, Tom; KLINE, T. Jefferson. (Ed.) A companion to Jean-Luc Godard. Oxford e Malden: Wiley-Blacwell, 2014. E-book, p 760-814.

NARBONI, Jean; MILNE, Tom (Ed.). Godard on Godard: critical writings by Jean-Luc Godard. Nova lorque e Londres: Da Capo Press, 1972.

RANCIÈRE, Jacques. Sobre Políticas Estéticas. Barcelona: Universitat Autónoma de Barcelona, 2005.

STERRITT, David. The Films of Jean-Luc Godard: seeing the invisible. Cambridge: Cambridge University Press, 1999. 